\title{
Allelopathic properties of the fractions obtained from sunflower leaves using supercritical carbon dioxide: The effect of co-solvent addition
}

\author{
Z. El Marsni ${ }^{a}$, L. Casas ${ }^{a}, *$, C. Mantell ${ }^{a}$, M. Rodríguez ${ }^{a}$, A. Torres ${ }^{b}$, \\ F.A. Macias ${ }^{\text {b }}$, E.J. Martínez de la Ossa ${ }^{a}$ \\ a Department of Chemical Engineering and Food Technology, Faculty of Science, University of Cadiz, Campus de Excelencia International Agroalimentario \\ ceiA3, Box 40, 11510 Puerto Real, Cadiz, Spain \\ ${ }^{\mathrm{b}}$ Department of Organic Chemistry, Faculty of Science, University of Cadiz, Campus de Excelencia International Agroalimentario ceiA3, Box 40,11510 \\ Puerto Real, Cadiz, Spain
}

\section{A R T I C L E I N F O}

\section{Article history:}

Received 24 June 2013

Received in revised form 26 July 2013

Accepted 29 July 2013

\section{Keywords:}

Allelopathy

Bioactive substances

Herbicides

Supercritical fluid extraction

\begin{abstract}
A B S T R A C T
The work described here is a continuation of a previous study centered on the extraction, using supercritical carbon dioxide, of bioactive substances from sunflower leaves of the Helianthus annuus L. variety Arianna. In this study the addition of $9 \%$ of ethanol as co-solvent was analyzed. The extraction was carried out $\left(P=100 / 400 \mathrm{bar}, T=35 / 55^{\circ} \mathrm{C}\right.$, ethanol $\left.=9 \%\right)$ in order to analyze the influence of pressure, temperature and sample pre-treatment on the extraction yield and bioactivity of the extracts. The addition of $9 \%$ of ethanol to the supercritical solvent enhanced both the extraction yield and the biological activity of the extracts. The best conditions were a pressure of 400 bar and a temperature of $55^{\circ} \mathrm{C}$. In an effort to improve the bioactivity of the extract, a cascade fractionation of the extracts was carried out and this gave different results in terms of biological activities and extraction yields. The phytochemical compositions of the extracts were analyzed by thin layer chromatography. The fractionation that gave the best results was carried out at 90 bar and $40^{\circ} \mathrm{C}$ in the first separator. Finally, the effect of extracts on the growth of seeds from different plants was analyzed.
\end{abstract}

(c) 2013 Elsevier B.V. All rights reserved.

\section{Introduction}

The current interest in pollution-free agriculture has led to the prohibition or restriction of several herbicides and this has encouraged the search for natural herbicides. Vegetable products such as composite allelochemicals constitute an attractive source of active compounds, not only due to their chemical diversity but also for their biological action as pesticides and their less harmful nature for the environment and human health. This latter advantage arises because such compounds are easily biodegradable and many of them are safe and clean. The number of functional compounds recovered from plant raw material depends on both the plant type and the method used for the extraction. The sunflower is undoubtedly one of the most useful plants both in terms of the amount of plant matter that can be obtained from a widespread crop and the large number of metabolites that it contains, principally in the leaves of the plant [1,2]. Extraction with supercritical fluids (SFE) has been used as an alternative to conventional methods of

\footnotetext{
* Corresponding author. Tel.: +34 956016 579; fax: +34 956016411.

E-mail address: lourdes.casas@uca.es (L. Casas).
}

extraction and/or fractionation. The addition of modifiers or cosolvents to $\mathrm{CO}_{2}$ improves the efficiency of the extraction by increasing the solubility of the solute and the extraction yields [3]. Among the organic solvents, ethanol has been widely used as a cosolvent in the extraction of bioactive compounds due to its low toxicity in comparison to other alternatives [4,5].

One of the easiest ways to assess allelopathic properties is to employ bioassays, in which the germination or emergence of seedlings is quantified and the length of the root or stem is measured. Various types of bioassay have been reported in the literature, including wheat coleoptile bioassays $[1,6]$ and others related to phytotoxicity [7] and hydroponic conditions [8].

The bioactive properties of supercritical extracts have been reported in numerous papers [9-15]. The supercritical extraction of sunflower leaves to give an extract with a high bioactive capacity has been studied recently. The effects of pre-treatment, pressure, temperature and co-solvent addition have been analyzed and good results have been obtained [3,9-11]. Nevertheless, in these studies the bioactivity of the extract was only assessed in a general bioassay and allelopathic properties were not analyzed apart from the results in the previous publication in this series [12]. In the previous work we extracted bioactive substances from the leaves of 
three varieties of sunflower (Stella, Hilian and Arianna) using pure $\mathrm{CO}_{2}$ as solvent. The extractions were carried out at temperatures of $35^{\circ} \mathrm{C}$ and $55^{\circ} \mathrm{C}$ and pressures of 100 bar and 400 bar. The results indicated that the best extraction yields and activity profiles were obtained with the Arianna variety at a pressure of 400 bar and a temperature of $55^{\circ} \mathrm{C}$. The results also showed that fractionation of the resulting extracts improves their biological activity, but the potential allelopathic properties of the fractionated extracts are not comparable to those of a commercial herbicide (Logran ${ }^{\circledR}$ ).

In an effort to improve on the previous results, the objective of the present study was to increase the extraction yields through the addition of $9 \%(\mathrm{v} / \mathrm{v})$ ethanol to carbon dioxide and to increase the biological activity of the extracts obtained. The fractionation process was investigated in cascade using ethanol as co-solvent under different conditions of pressure and temperature. The allelopathic properties of the resulting extracts were analyzed using three bioassays: (i) general activity bioassays on wheat coleoptiles, (ii) a phytotoxicity bioassay carried out on tomato, lettuce, onion and watercress seeds, and (iii) a bioassay carried out under hydroponic conditions. The results were compared with those obtained with a synthetic commercial herbicide $\left(\operatorname{Logran}^{\circledR}\right)$ and with the results reported in the previous paper, where extracts were obtained with carbon dioxide alone as solvent [12].

\section{Materials and methods}

\subsection{Raw material}

The raw material used in this study consisted of sunflower leaves (Helianthus annuus L.) of the variety Arianna. The leaves were cultivated at the 'Rancho de la Merced' of the Andalusia Institute of Agricultural and Fishery Research and Training (Junta of Andalusia, Jerez de la Frontera, Spain). The leaves were collected manually in June 2009 during the third growth stage of the plant (plant with flowers, around $1 \mathrm{~m}$ in height), since it has been found that at this stage the plant shows greater phytotoxicity [2]. One portion of the leaves was congealed at $-25^{\circ} \mathrm{C}$ and the other portion was air-dried on blotting paper to constant weight.

\subsection{Supercritical fluid extraction}

The first part of the study into extraction conditions (concerning the influence of pressure and temperature on the extraction yields obtained from dried and congealed samples) was carried out in equipment supplied by Thar Technology (Pittsburgh, PA, USA, model SF100). The equipment used included an extraction vessel (capacity of $100 \mathrm{~mL}$ ) and two double piston pumps with a maximum flow rate of $50 \mathrm{~g} / \mathrm{min}$, one for $\mathrm{CO}_{2}$ and the other for co-solvent. A thermostatic jacket allowed control of the extraction temperature. The cyclonic separator allowed the periodic discharge of the extracted material during the SFE process. The procedure used is the same as that described in the previous publication [12] but with the addition of ethanol (99.9\% purity, Panreac) as co-solvent. Extracts were dried at the same temperature as applied in the extraction process in a rotary evaporator under vacuum.

The second part of the study (fractionation process) was carried out in a Thar Technology SF2000 system equipped with an extractor (2 L capacity), two cyclonic separators ( $500 \mathrm{~mL}$ each) connected in series, and with two high pressure pumps; one for $\mathrm{CO}_{2}$ (P200 model), capacity of $200 \mathrm{~g} / \mathrm{min}$, and the other for the co-solvent (P50 model).

\subsubsection{Extraction and fractionation conditions}

The extractions were conducted at temperatures of 35 and $55^{\circ} \mathrm{C}$ and pressures from 100 to 400 bar on congealed and dried samples. The flow rate measured for the supercritical fluid was $20 \mathrm{~g} / \mathrm{min}$ of
$\mathrm{CO}_{2}$ and $2 \mathrm{~g} / \mathrm{min}$ of ethanol during $3 \mathrm{~h}$. This amount of co-solvent was selected because it is the minimum amount of ethanol that can be supplied by the pump. In previous studies with other systems, we concluded that a minimum amount of co-solvent gives better bioactivity results [3].

The same solvent system, i.e. a mixture of $\mathrm{CO}_{2}$ and $9 \%(\mathrm{v} / \mathrm{v})$ ethanol, was used for the fractionation. The best extraction conditions were used in the extractor $\left(55^{\circ} \mathrm{C}\right.$ and 400 bar $)$ and four fractionation conditions were tested. These conditions are listed below:

- Extraction 1 (E1) - conditions in separator 1: 200 bar and $45^{\circ} \mathrm{C}$, atmospheric conditions in separator 2 .

- Extraction 2 (E2) - conditions in separator 1: 100 bar and $40^{\circ} \mathrm{C}$, atmospheric conditions in separator 2 .

- Extraction 3 (E3) - conditions in separator 1: 90 bar and $40^{\circ} \mathrm{C}$, atmospheric conditions in separator 2 .

- Extraction 4 (E4) - conditions in separator 1: 70 bar and $40^{\circ} \mathrm{C}$, atmospheric conditions in separator 2.

\subsection{Bioassays}

Three different bioassays were employed to test the extracts obtained. The methodology involves the preparation of solutions with different concentrations of the extract $(1000 \mathrm{ppm}, 500 \mathrm{ppm}$, $250 \mathrm{ppm}, 125 \mathrm{ppm}, 75 \mathrm{ppm}$ for the coleoptile bioassay and $800 \mathrm{ppm}$, 400 ppm, 200 ppm for phytotoxicity tests in Petri dishes and hydroponic bioassay conditions) and the addition of coleoptiles or seeds. The length of the coleoptiles or the length of the root or stem is then evaluated. A more detailed description of the bioassays is presented in a previous publication [12].

Coleoptile bioassay: This is a relatively simple test used as a step prior to the evaluation of bioactive agents. The test involves analysis of the elongation of apical zones of cereals (wheat in this case) in the presence of liquid media containing the potentially allelopathic agents.

Phytotoxicity tests in Petri dishes: This assay reproduces the natural conditions for the performance of products to be tested on the seeds of selected plant species. The range of concentrations used allows an evaluation of the relationship between the phytotoxic activity of the product and its concentration. The selection of species is detailed in the bibliography [7]. The species tested were as follows: monocot Allium cepa L. (onion) and the dicots Lepidium sativum L. (watercress), Lactuta sativa L. (lettuce) and Lycopersicum esculentum L. (tomato).

Hydroponic bioassay conditions: Researchers have used this technique to study the secondary metabolites produced by plants grown under hydroponic conditions with a nutrient solution used as support [8]. This assay is a higher step to examine the activity of the selected statement and determine the potential of metabolites as a basis for the future design of model natural herbicides.

\subsection{Thin layer chromatography}

Thin layer chromatography (TLC) was carried out on Alugram Sil G/UV254 (Macherey Nagel) $0.25 \mathrm{~mm}$ thick plates. The detection of the different compounds was carried out by exposure to UV light (254-365 nm) and plates were developed chemically with oleum prepared with sulfuric acid (Panreac 98\%), water and acetic acid (Panreac 100\%) (1:4:20) with subsequent heating at $150{ }^{\circ} \mathrm{C}$. Mixtures of hexane/acetone (60:40 (v/v)) were used as the eluent.

\subsection{Cluster analysis}

Statistical treatments were performed using the program STATGRAPHICS Plus 4.0 (Statistical Graphics Corp. 1994-1999). 


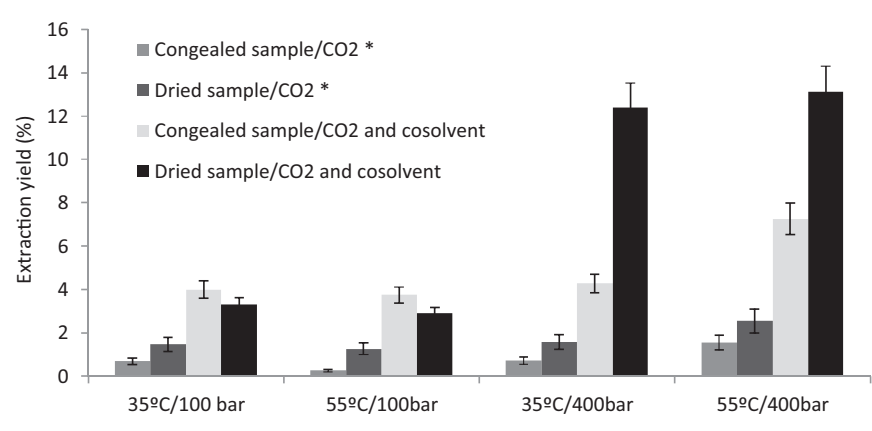

Fig. 1. Extraction yields obtained in this work from the Arianna variety using $\mathrm{CO}_{2}$ + ethanol as solvent and *data published previously and obtained using pure $\mathrm{CO}_{2}$ as solvent [12].

Association analysis of the data based on the bioactivity profile was performed for each of the different sets of extraction conditions.

To clarify further the relationships between the clusters and those individuals forming the clusters, a dendrogram was generated by hierarchical cluster analysis; the squared Euclidean distance between normalized data was used to measure the similarity between samples.

\section{Results and discussion}

\subsection{Extraction}

The influence of pressure and temperature on the extraction yields obtained from dried and congealed samples of the variety Arianna was investigated at temperatures of $35-55^{\circ} \mathrm{C}$ and pressures of $100-400$ bar, using mixtures of supercritical $\mathrm{CO}_{2}$ and $9 \%(\mathrm{v} / \mathrm{v})$ ethanol. The results are shown in Fig. 1. The data obtained with pure $\mathrm{CO}_{2}$ were reported in a previous publication [12] and are included in Fig. 1 for the sake of comparison.

It is well known that extraction temperature and pressure are the two most important parameters in SFE because they are the major determinants of solvent power and can have a marked influence on extraction efficiency. The isothermal increase from 100 to 400 bar of pressure led to an increase in the extraction yields. This behavior is usually attributed to the increase in the density of the solvent and the consequent increase in the solvent power of the carbon dioxide + ethanol system. At 100 bar, an increase in temperature did not lead to a significant decrease in the extraction yield, except for the case of the congealed sample extracted with pure $\mathrm{CO}_{2}$, in which case an increase in temperature led to a more marked decrease in the extraction yield. At 400 bar, however, a greater increase in extraction yield was obtained when congealed samples were processed.

The effect of co-solvent effect is complex. On the one hand, the use of a co-solvent produces a change in the polarity of the solvent that increases the yield of extraction of polar substances. On the other hand, it is possible to cause swelling of the matrix and this can facilitate the release of the active sites of solutes within the matrix. The moisture present in the sample is another complex factor because there is competition between the solvent and water present in the sample.

Regarding the effect of sample pre-treatment, at 400 bar dried samples gave better extraction yields than congealed samples. The humidity levels of the samples when the extraction was carried out with $9 \%(v / v)$ co-solvent had a significant effect on the results of the extraction process. At this high pressure the humidity of the leaves alters the structure of the sample and this changes the diffusion of the supercritical fluid. This situation has a negative effect on the efficiency of the extraction process. The same behavior was observed when the process was carried out without co-solvent $[10,12]$.

Different behavior was observed at a pressure of 100 bar. A slight increase in the extraction yield was achieved when the sample was previously congealed in comparison to the results obtained with the dried sample. This situation is quite different to those obtained when co-solvent was not added to the solvent system. Probably the competitive effect of the solvent water becomes unimportant when adding the co-solvent.

Comparison of the results discussed above with those obtained in a previous study [12] confirms the hypothesis that the use of $9 \%$ ethanol as co-solvent increases the efficiency of the extraction process with supercritical carbon dioxide. For congealed samples, the extraction yield is 5 times higher when co-solvent is used in comparison to that obtained with the pure solvent system. For dried samples, at 100 bar this increase is 2 times and at 400 bar the yield increases by a factor of 6 . This improvement is due to the fact that ethanol increases the solubility of solutes, thus enhancing the polarity of the supercritical fluids and facilitating the withdrawal of solute from the plant array. Similar outcomes were observed in the SFE of flavonoids from Scutellariae Radix [16] and of isoflavones from soybean meal [17].

\subsubsection{Coleoptile bioassay}

In order to select the conditions that provide extracts with the best biological activity it was necessary to carry out a bioassay to assess overall activity. In general, the more bioactive the extract, the greater its potential allelopathic properties. The objective of this study was not to determine specific values but to obtain activity

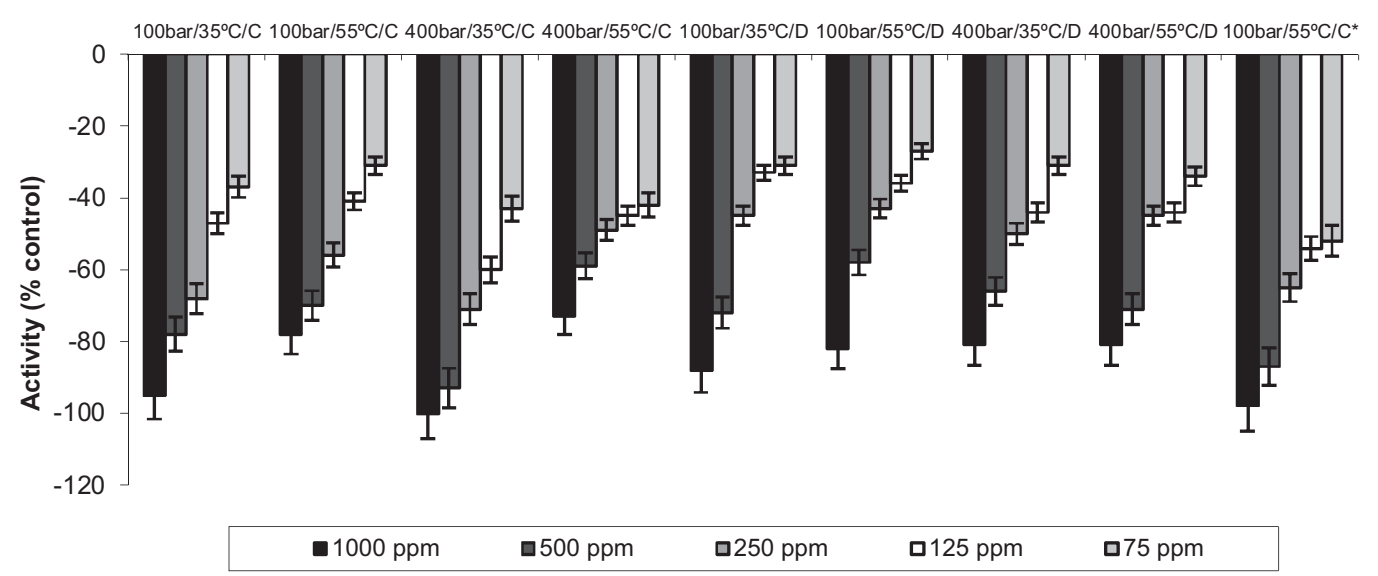

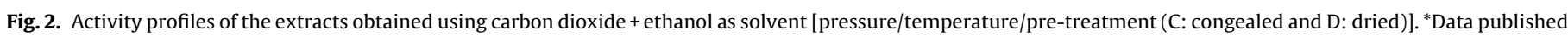
previously for extracts obtained using pure $\mathrm{CO}_{2}$ as solvent for the best activity profile [12]. 


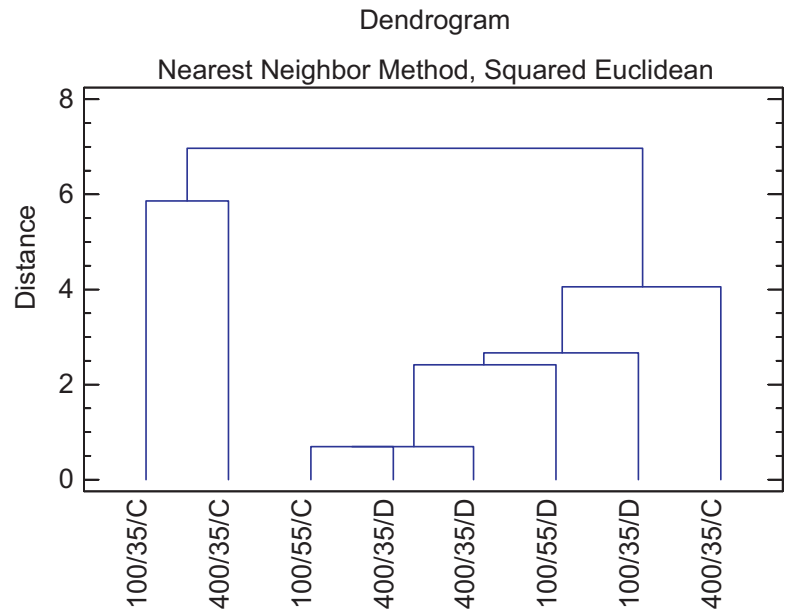

Fig. 3. Results of the cluster analysis on the bioactivity of the extracts obtained with carbon dioxide + ethanol from samples of sunflower leaves [pressure/temperature/pre-treatment (C: congealed and D: dried)].

profiles on the basis that the extracts are more bioactive if their activity levels persist upon dilution of the sample.

The activity profiles, along with results for the control, of extracts obtained with supercritical carbon dioxide and $9 \%(\mathrm{v} / \mathrm{v})$ ethanol as co-solvent at pressures of 100 bar and 400 bar and temperatures $35^{\circ} \mathrm{C}$ and $55^{\circ} \mathrm{C}$ with different pre-treatments are shown in Fig. 2.

In this figure, the data are expressed as percentage differences from the control, which means that a value of zero represents an identical value to the control and a negative value represents inhibition of the growth of the wheat coleoptiles under the given experimental conditions.

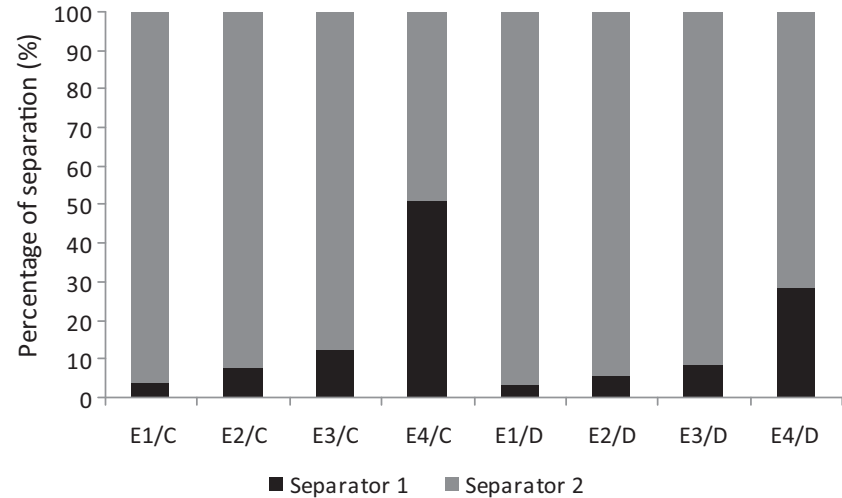

Fig. 4. Percentage separation of the extracts in the two separators, after the extraction process carried out at 400 bar and $55^{\circ} \mathrm{C}$ [extraction number/pre-treatment (C: congealed and D: dried)].

The extract is considered to be more bioactive when its activity levels persist as the sample is diluted. It can be seen that all extracts show strong inhibition with increasing dilution. Comparison of these results with those obtained in a previous study [12], in which pure $\mathrm{CO}_{2}$ was used for the extraction, confirms that the use of ethanol as co-solvent increases the biological activity of extracts. The dried samples, extracted with $\mathrm{CO}_{2}+$ ethanol, have lower activity profiles than congealed samples, although this decrease is less marked than in the case of the extractions with pure $\mathrm{CO}_{2}$.

Cluster analysis highlights the groups with similar profiles and the results of this analysis are shown in Fig. 3. The best activity profiles were obtained with congealed samples extracted at $35^{\circ} \mathrm{C}$ and at the two pressures studied (100 and 400 bar); these conditions

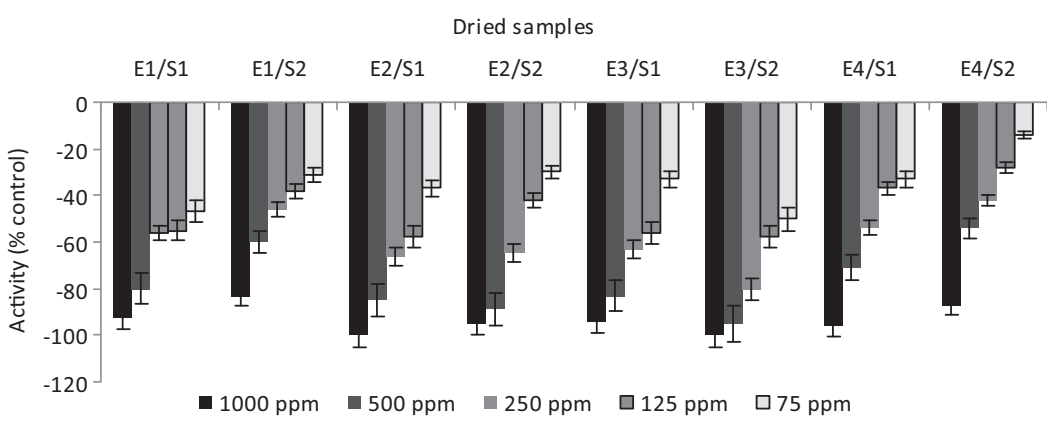

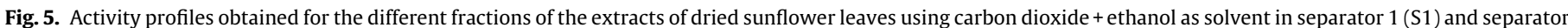
2 (S2).

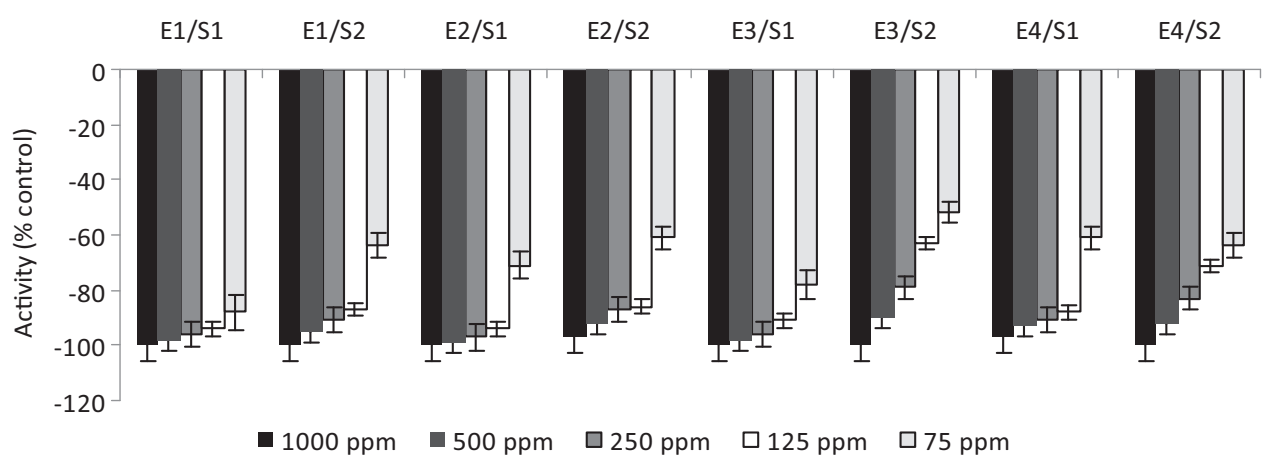

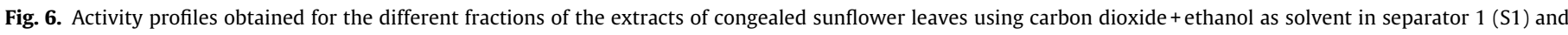
separator $2(\mathrm{~S} 2)$. 


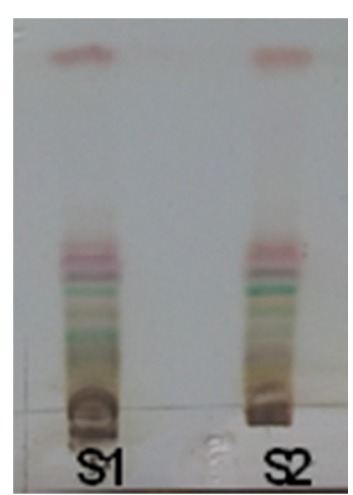

Fig. 7. Thin layer chromatogram of the fractions obtained in E3 from dried samples: S1 (separator 1) and S2 (separator 2).

give rise to a first group of extracts, which show higher persistence of the activity with increasing dilution. The second group is formed by samples obtained using other extraction conditions tested and these extracts exhibit similar activity behavior, with lower activity levels compared with the first group.

\subsection{Fractionation of the extracts}

The best extraction yields were obtained from dried samples when operating at 400 bar and $55^{\circ} \mathrm{C}$. However, the cluster analysis shows that the extracts with the best bioactivity profiles were obtained at 100 bar and $35^{\circ} \mathrm{C}$ and 400 bar and $35^{\circ} \mathrm{C}$ on using congealed samples. The rapid extraction at 100 bar led to low yields and we therefore decided to continue to work at 400 bar and $55^{\circ} \mathrm{C}$ with the aim of increasing the activity of the extracts by using a cascade fractionation. This methodology involves the gradual precipitation of the extracts obtained in the process by modifying the density of the supercritical solvent. This is achieved by changing the pressure and temperature in two cyclone separators connected in series. In this section the extraction yields for each separator and the activity levels obtained are discussed. Three types of biological assays were performed in order to study the behavior of these extracts.

The percentage separation (\%) for the fractionations carried out on dry and congealed samples on using a mixture of carbon dioxide and 9\% ethanol as co-solvent are shown in Fig. 4.

For both types of pre-treated sample (dried and congealed) the best percentage of precipitated compounds was obtained in the second separator (S2). The less soluble compounds will remain
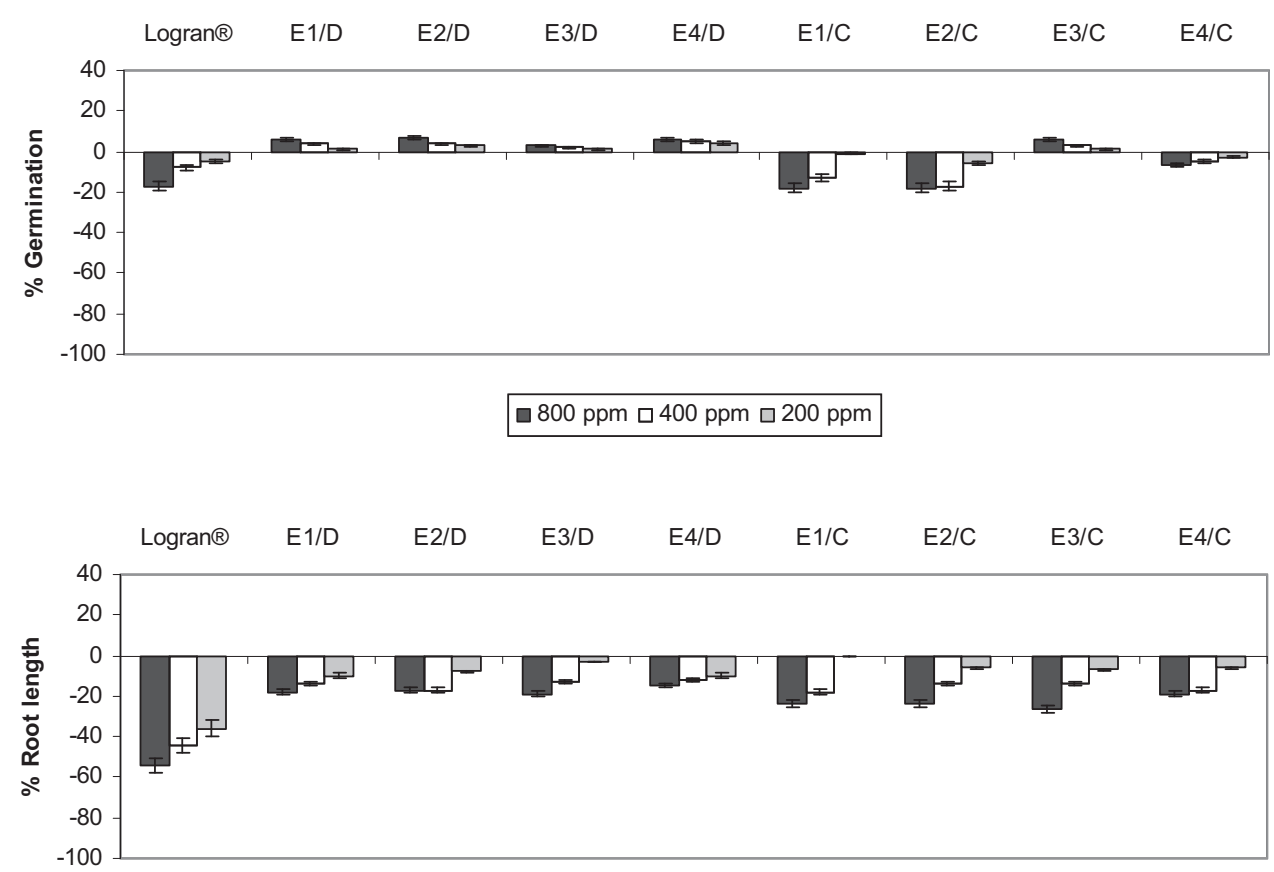

800 ppm $\square 400$ ppm $\square 200$ ppm

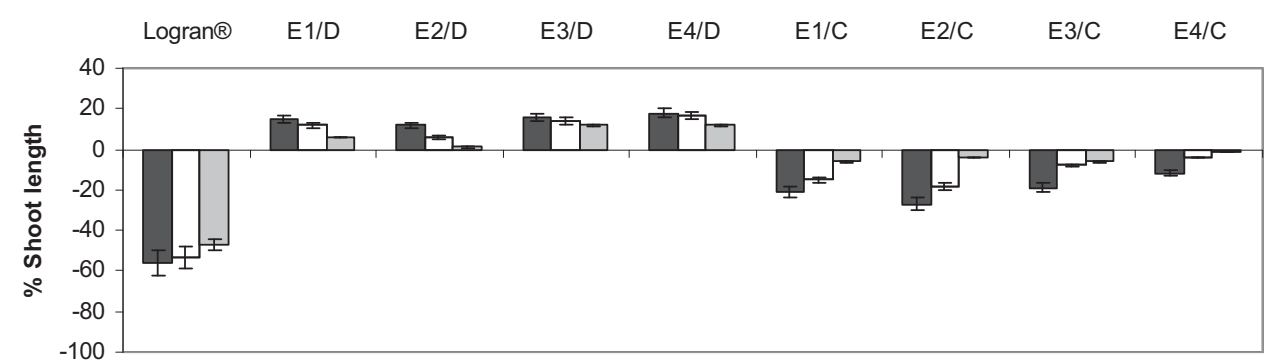

$\square 800$ ppm $\square 400$ ppm $\square 200$ ppm

Fig. 8. Results of the phytotoxicity bioassay applied to cress [extraction number/pre-treatment (C: congealed and D: dried)]. 

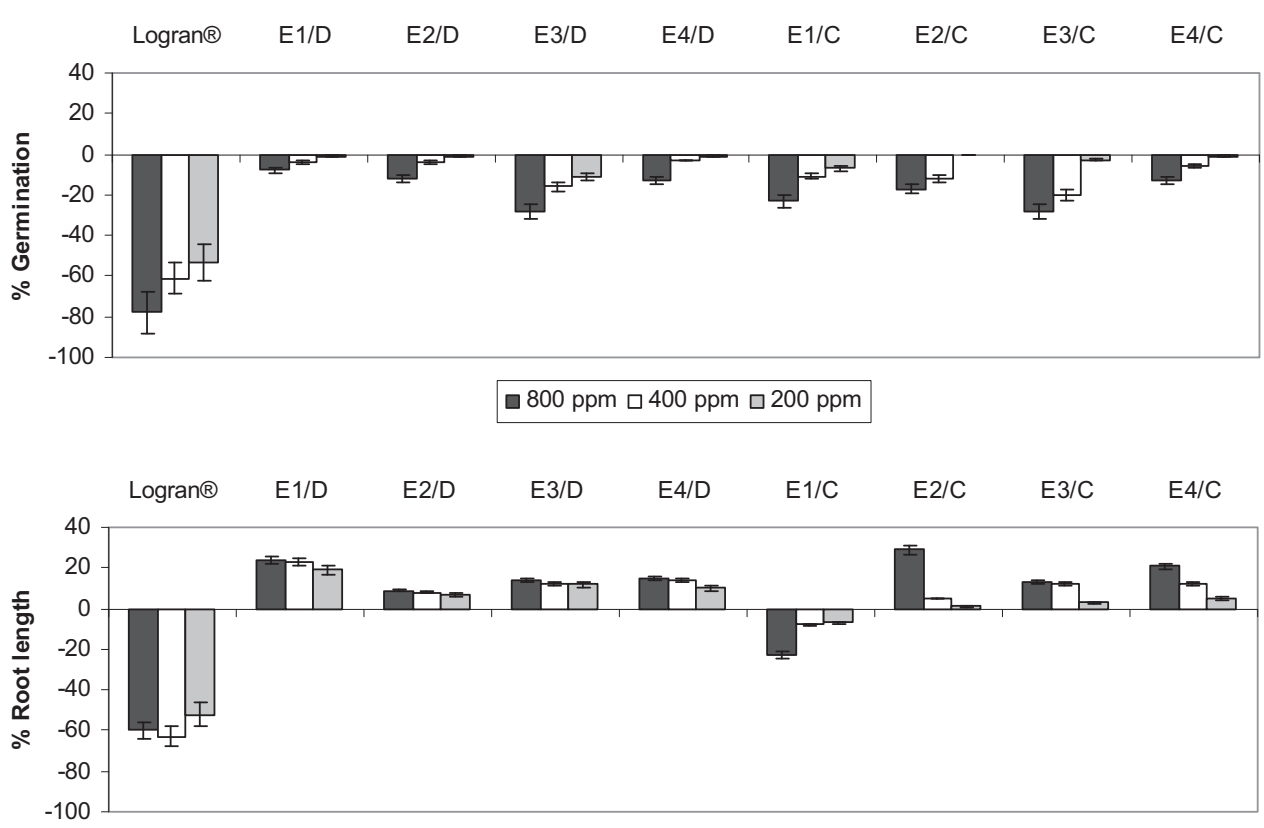

$\square 800$ ppm $\square 400$ ppm $\square 200$ ppm

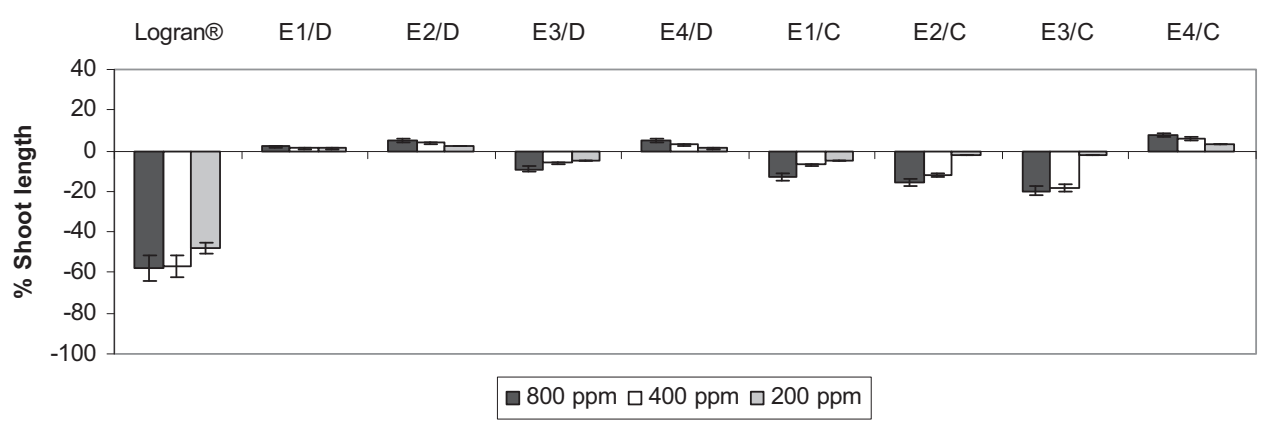

Fig. 9. Results of the phytotoxicity bioassay applied to lettuce [extraction number/pre-treatment (C: congealed and D: dried)].

in the first separator, while the more soluble compounds pass to the second separator. It is worth noting the test carried out on congealed samples in (E4), where the percentage of precipitated compounds is very similar in both separators. It can be inferred from this result that when the process is carried out on congealed samples, the mass transfer of less soluble compounds is better than that obtained in the extraction of dry samples.

Comparison of these results with those obtained in a previous study [12] leads to the conclusion that the mass percentage of the yields obtained in the second separator (S2) increase to a greater extent in the case of SFE with co-solvent. For example, in E4 from congealed samples the mass percentage increases from $28 \%$ in the extraction with $\mathrm{CO}_{2}$ to $48 \%$ in the extraction with $9 \%$ ethanol as co-solvent and from dried samples the increase is from $12 \%$ in the extraction with $\mathrm{CO}_{2}$ to $71 \%$ in the extraction with $9 \%$ ethanol as cosolvent. This finding indicates that the efficiency of ethanol as a cosolvent increases the capacity of the extracted mixture to remove more soluble substances.

\subsubsection{Coleoptile bioassay}

In an analogous way to the extraction process, the activity of each of the fractions was assessed in order to identify the most active samples obtained by fractionation. Activity profiles for the extracts obtained from both dried and congealed samples in the fractionation process are presented in Figs. 5 and 6, respectively. The results for the control are also shown. This assay was performed on extracts obtained from both separators (S1 and S2) with the process carried out using mixture of supercritical $\mathrm{CO}_{2}$ and $9 \%(\mathrm{v} / \mathrm{v})$ ethanol as co-solvent.

Analysis of the results shown in Fig. 5 indicates that all activity profiles lead to strong inhibition in the growth of the coleoptiles. The extract from the fraction obtained in experiment E3 ( $90 \mathrm{bar} / 40^{\circ} \mathrm{C}$ ) in the second separator (S2) shows the best persistence in inhibition on increasing dilution. At $1000 \mathrm{ppm}$ the activity value is $-100 \%$ and this only decrease to $-80 \%$ at $250 \mathrm{ppm}$. The dilution of $75 \mathrm{ppm}$ shows $-50 \%$ inhibitions.

It can be seen from Fig. 6 that congealed samples give rise to better activity profiles than dried samples. The materials obtained in experiments E1, E2 and E3 in the first separator (S1) show the best profiles in terms of inhibitory activity as the variations in activity are very small on increasing dilution. However, in general it can be seen that all extraction conditions for both separators give extracts with excellent performance in terms of activity as very little variation is seen on increasing dilution. The results obtained at a dilution of $75 \mathrm{ppm}$ in all cases exceed $-50 \%$ inhibitions.

Regarding the previously published results for the process carried out with pure carbon dioxide as solvent [12], it can clearly be seen that a notable improvement in the activity is achieved by adding a co-solvent. These results support the hypothesis that the extraction of compounds with ethanol as co-solvent increases of the amount of substances obtained and also changes the nature of the active substances extracted. 

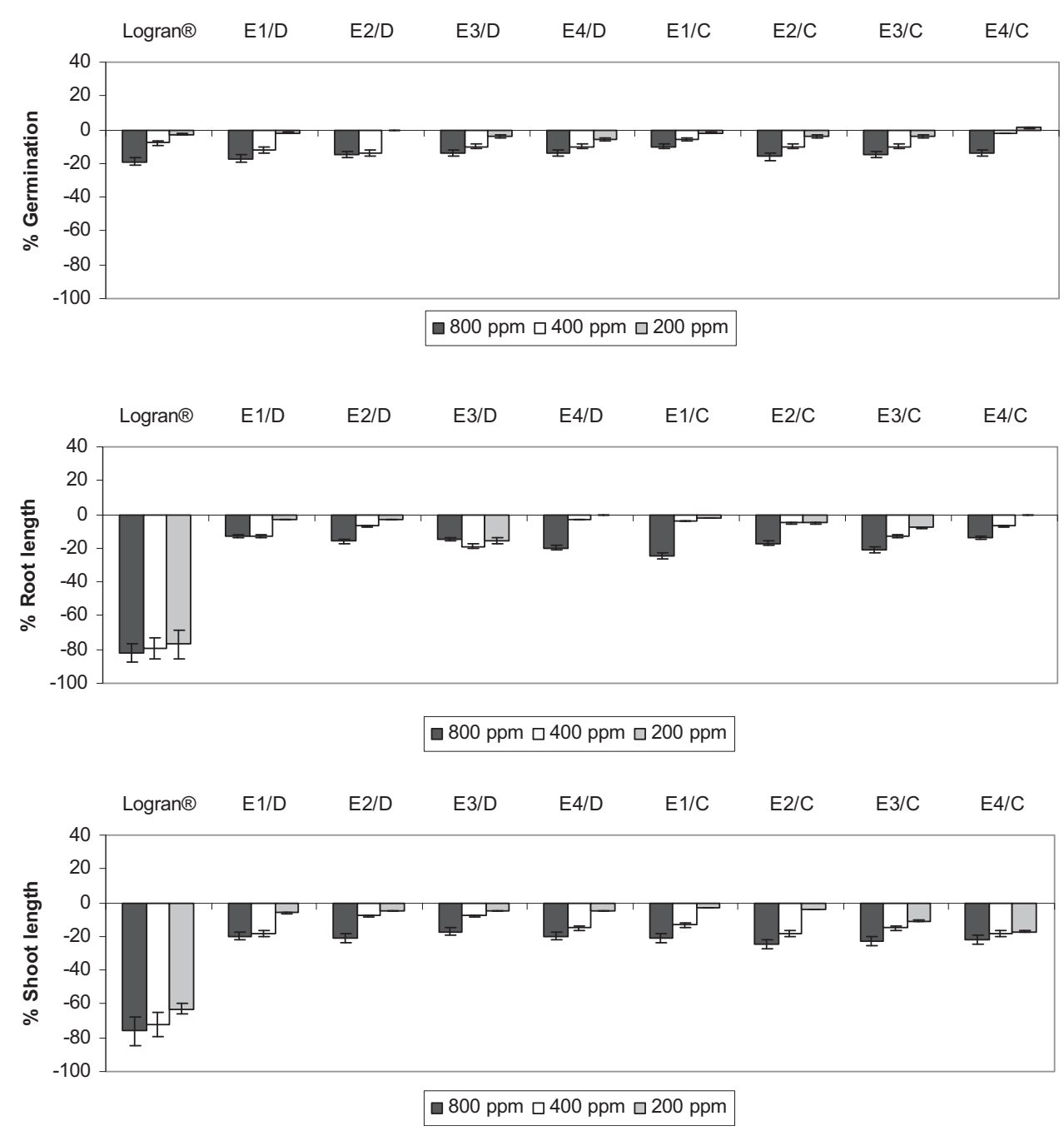

Fig. 10. Results of the phytotoxicity bioassay applied to onion [extraction number/pre-treatment (C: congealed and D: dried)].

It can be seen from Figs. 5 and 6 that there are no clear differences between the activity levels of the extracts obtained under different fractionation conditions. However, to obtain further information about the fractions it was necessary to perform qualitative analysis by thin layer chromatography (TLC). The chromatograms for the dried samples obtained in the two separators ((S1) and (S2)) are shown in Fig. 7. This technique does not show clear differences between the substances precipitated in each separator.

The coleoptile bioassay did not differentiate between the biological activities of the various fractions. As a consequence, a phytotoxicity bioassay was carried out on extracts obtained in separator 2 as these had higher extraction yields.

\subsubsection{Phytotoxicity bioassay}

In the phytotoxicity bioassay the results were compared with those of the herbicide Logran ${ }^{\circledR}$, which is a commercial product of the company Syngenta (Spain). Three parameters were evaluated: $\%$ germination, \% root length and \% shoot length. The results of the phytotoxicity test applied to cress, lettuce, onion and tomato seeds using extracts obtained in S2 from dried and congealed samples are shown in Figs. 8-11. The data are expressed as percentage difference from the control, which means that a value of zero represents an identical value to the control, a positive value represents stimulation of the parameter in question and a negative value represents inhibition of the growth of the wheat coleoptiles under the given experimental conditions.

$\operatorname{Logran}^{\circledR}$ shows accentuated levels of inhibition for the three parameters tested (seed germination, growth of the stem and root) for the four seeds studied. This herbicide not does show an adequate response in the \% germination of cress and onion seeds. This difference is due the fact that the behavior of the herbicide against each seed is different.

In the cases of lettuce, onion and cress the levels of inhibition/growth did not rise above the $25 \%$ obtained for the highest extract concentration. These results show that the effect of the extract on the target species is very low or practically zero. In contrast, good results were obtained in all of the assays carried out with tomato.

The best profiles with tomato in terms of \% germination were obtained for E3 and E4 as the activity levels persisted on increasing dilution. The \% root length of E3/C is similar to that of Logran ${ }^{\circledR}$ and the behavior of E4/C was also good. For dried samples E3/D showed greater persistence with increasing dilution. At $800 \mathrm{ppm}$ the inhibition level was $-84 \%$ and at 200 ppm it was $-43 \%$. A plant that has problems with root growth suffers from poor nutrition and the plant ends up dying. The congealed samples showed the best inhibitory effect of \% shoot length. Fractions E3/C and E2/C presented the best activity profiles. 

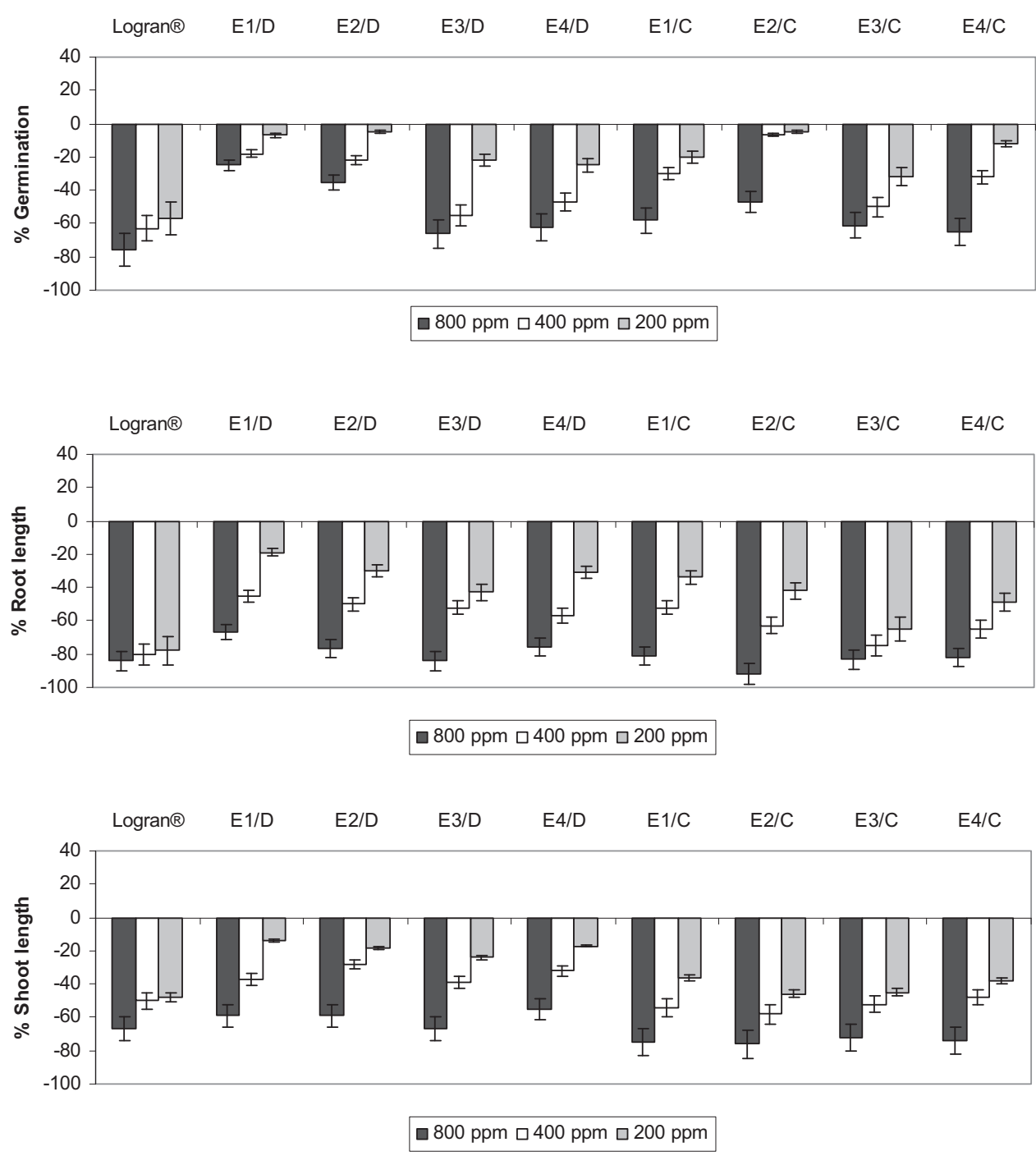

Fig. 11. Results of the phytotoxicity bioassay applied to tomato [extraction number/pre-treatment (C: congealed and D: dried)].

Even though good results were obtained in this phytotoxicity bioassay for tomato seeds, it can be concluded that a laboratory bioassay is not sufficiently sensitive to demonstrate that allelopathy is operational in natural settings. The extracts obtained for fraction E3 $\left(90 \mathrm{bar} / 40^{\circ} \mathrm{C}\right)$ in S2 from congealed and dried samples are the most similar to the commercial herbicide Logran ${ }^{\circledR}$. However, fraction E3 obtained from congealed samples showed better inhibition in comparison to E3 obtained from the dried sample, but it is desirable to work with dried samples because the extraction yields are greater. Furthermore, it was intended to exploit sunflower leaves to obtain bioactive compounds and such plants are usually found in dry regions that are not particularly cold.

It was therefore necessary to perform a bioassay under hydroponic conditions. The possible effects of the different replicates were compared with a control and samples were analyzed daily until the first symptoms were detected.

The quantitative effect produced is represented in Fig. 12 and these results corroborate the inhibition produced by the solution of the extract. Significant growth inhibition of stems $(-80 \%)$ and roots $(-67 \%)$ of the tomato plant was obtained at $800 \mathrm{ppm}$. The activity on shoot length showed better persistence of inhibition on increasing dilution in comparison to the activity on the root length.

Comparison of the results of the test under hydroponic conditions applied to fraction E3, obtained with pure carbon dioxide [12] or mixtures of carbon dioxide and 9\% (v/v) ethanol shows that both extracts inhibit the growth of tomato seedlings.

\subsection{Kinetics of fractionation}

It was decided to study the kinetics of fractionation in order to identify the best flow rate and extraction times for the process. The extraction conditions were 400 bar and $55^{\circ} \mathrm{C}$ and in the

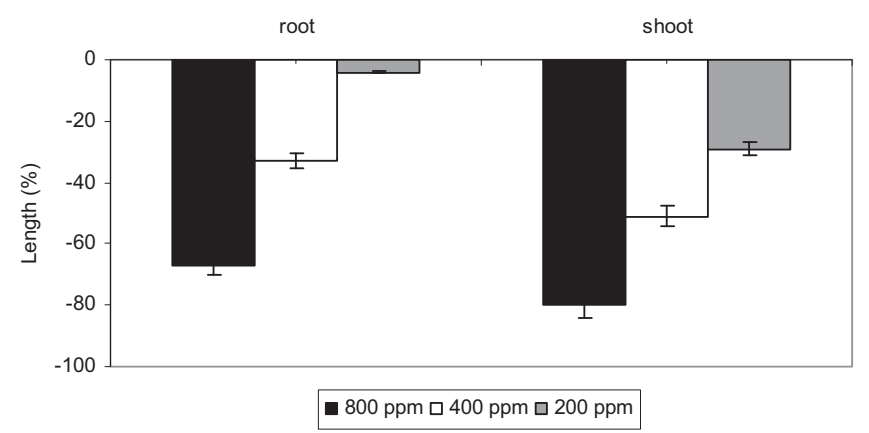

Fig. 12. Assay under hydroponic conditions for the fraction obtained from separator 2 at 90 bar $/ 40^{\circ} \mathrm{C}$ with dried samples. 


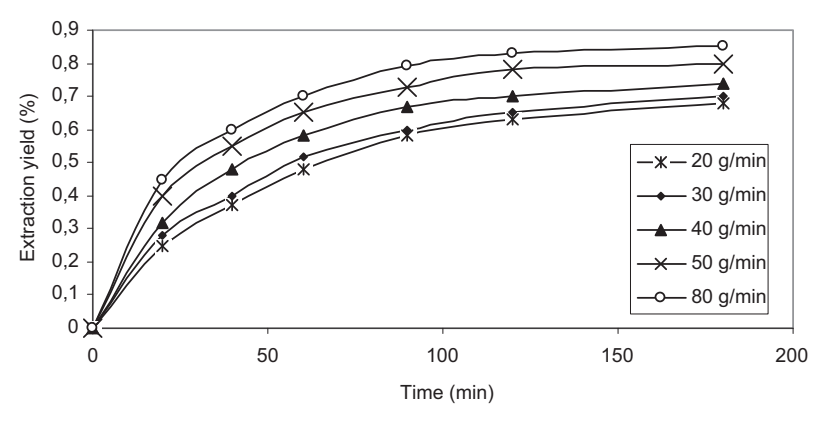

Fig. 13. Extraction yields for different extraction times.

first separator 90 bar and $40^{\circ} \mathrm{C}$. The percentage of ethanol used in each experiment was $9 \%$ and the samples were dried prior to the extraction process.

The extraction yields are shown in Fig. 13 for different extraction times. Each experimental point on the extraction curve represents the average of two independent experiments with a reproducibility of approximately $9 \%$ coefficient of variation.

It can be seen that the recovery is very dependent on the flow rate. The experimental results indicate a higher extraction yield for the process with a solvent flow rate of $80 \mathrm{~g} / \mathrm{min} \mathrm{CO}_{2}$ than at $20 \mathrm{~g} / \mathrm{min} \mathrm{CO}_{2}$. Generally, an increase in the flow rate leads to higher yields of extracts. This effect is due to the presence of larger amounts of solvent in the operation, a factor that improves the extraction yield. However, the solvent consumption was very high at a flow rate of $80 \mathrm{~g} / \mathrm{min}$. A flow rate of $20 \mathrm{~g} / \mathrm{min}$ gave an extraction yield that was $80 \%$ of that obtained at $80 \mathrm{~g} / \mathrm{min}$, but the consumption of $\mathrm{CO}_{2}$ was reduced by $75 \%$.

It can also be seen from Fig. 13 that the kinetics of the process lead to asymptotic curves. At all flow rates studied, the extraction yields from $120 \mathrm{~min}$ to $180 \mathrm{~min}$ were only $7 \%$ or less and the consumption of carbon dioxide was 33\% of the total consumption of solvent in the process. This analysis indicates that the most appropriate extraction time is approximately $120 \mathrm{~min}$.

\section{Conclusions}

The addition of $9 \%(v / v)$ of ethanol as a co-solvent to supercritical carbon dioxide increases the efficiency of the extraction process, which in turn leads to an increase in both the extraction yield and the biological activity. According to our results, the best extraction yield from leaves of sunflower variety Arianna, on using a mixture of carbon dioxide and $9 \%(\mathrm{v} / \mathrm{v})$ ethanol as solvent are obtained with dried samples at a pressure of 400 bar and a temperature of $55^{\circ} \mathrm{C}$. The best activity profiles in the coleoptile bioassay were obtained with congealed samples extracted at a temperature of $35^{\circ} \mathrm{C}$ and pressures of 100 and 400 bar.

In an effort to increase the activity of the extracts a cascade fractionation was carried out. The best extraction yields were obtained in the second separator. In the case of dried samples, the extract of the fraction obtained in experiment E3 $\left(90 \mathrm{bar} / 40^{\circ} \mathrm{C}\right)$ in the second separator showed the best persistence of inhibition on increasing dilution in the coleoptile bioassay. In the case of congealed samples, all extraction conditions in both separators gave excellent performance in terms of their activity levels. The phytotoxicity bioassay carried out on the extract obtained from the second separator gave excellent results with tomato seeds. The extracts obtained in fraction E3 ( $\left.90 \mathrm{bar} / 40^{\circ} \mathrm{C}\right)$ in S2 from dried and congealed samples are the most similar to the commercial herbicide Logran ${ }^{\circledR}$. A hydroponic bioassay on tomato seeds was performed and inhibition in the growth of the shoot and the root was observed.

\section{Acknowledgements}

The authors wish to thank to the staff at the 'Rancho de la Merced' Research and formation center (Junta of Andalucía, Jerez de la Frontera, Spain) for providing the raw material.

\section{References}

[1] F.A. Macias, J.M.G. Molinillo, R. Varela, J.C.G. Galindo, Allelopathy: a natural alternative for weed control, Pest Management Science 63 (2007) 327-348.

[2] F.A. Macias, A. Oliveros-Bastidas, D. Marin, C. Carrera, N. Chinchilla, J.M.G. Molinillo, Plant biocommunicators: their phytotoxicity: degradation studies and potential use as herbicide models, Phytochemistry Reviews 7 (2008) 179-194.

[3] L. Casas, C. Mantell, M. Rodríguez, A. Torres, F.A. Macías, E. Martínez de la Ossa, Effect of the addition of co-solvent on the supercritical fluid extraction of bioactive compounds from Helianthus annuus L., Journal of Supercritical Fluids 41 (2007) 43-49.

[4] C.L. Chiu, Y.C. Cheng, J.H. Chen, C.J. Chang, P.W. Yang, Supercritical fluids extraction of Ginkgo ginkgolides and flavonoids, Journal of Supercritical Fluids 24 (2002) 77-87.

[5] A. De Lucas, I. Gracia, J. Rincon, M.T. Garcia, Solubility determination and mode] prediction of Olive Husk oil in supercritical carbon dioxide and co-solvents, Industrial and Engineering Chemical Research 46 (2007) 266-272.

[6] H.G. Cutler, in: P.A. Hedin (Ed.), Bioregulators for Pest Control, American Chemical Society, Washington, DC, 1985.

[7] F.A. Macias, D. Castellano, J.M.G. Molinillo, Search for a standard phytotoxic bioassay for allelochemicals. Selection of standard target species, Journal of Agricultural and Food Chemistry 48 (2000) 2512-2521.

[8] D.R. Hoagland, D.I. Arnon, The water culture methods for growing plants without soil, California Agricultural Experiment Station Circular (1950) 347.

[9] L. Casas, C. Mantell, M. Rodriguez, A. Torres, F.A. Macias, E. Martinez de la Ossa, Effect of the pre-treatment of the samples on the natural substances extracted from Helianthus annuus L. using supercritical carbon dioxide, Talanta 67 (2005) $175-181$.

[10] L. Casas, C. Mantell, M. Rodríguez, A. Torres, F.A. Macías, E. Martínez de la Ossa, Extraction of natural compounds with biological activity from sunflower leaves using supercritical carbon dioxide, Chemical Engineering Journal 152 (2009) 301-306.

[11] L. Casas, C. Mantell, M. Rodríguez, A. Torres, F.A. Macías, E. Martínez de la Ossa, SFE kinetics of bioactive compounds from Helianthus annuus L., Journal of Separation Science 32 (2009) 1445-1453.

[12] Z. El Marsni, L. Casas, C. Mantell, M. Rodríguez, A. Torres, F.A. Macias, E.J. Martínez de la Ossa, J.M.G. Molinillo, R.M. Varela, Potential allelopathic of the fractions obtained from sunflower leaves using supercritical carbon dioxide, Journal of Supercritical Fluids 60 (2011) 28-37.

[13] W. Shu-Jing, L. Shu-Jung, S. Chun-Han, L. Doung-Liang, W. Shyh-Shyan, N. LeanTeik, Bioactive constituents and anti-proliferative properties of supercritical carbon dioxide Salvia miltiorrhiza extract in 3T3-L1 adipocytes, Process Biochemistry 47 (2012) 216-224.

[14] P. Costa, C. Grosso, S. Gonçalves, P. Andrade, P. Valentão, M.G. Bernardo-Gil, A. Romano, Supercritical fluid extraction and hydrodistillation for the recovery of bioactive compounds from Lavandula viridis L'Hér, Food Chemistry 135 (2012) $112-121$.

[15] M.C. Mesomao, M.L. Corazza, P.M. Ndiave, O.R. Dalla Santa, L. Cardozo, A. de, P. Scheer, Supercritical $\mathrm{CO}_{2}$ extracts and essential oil of ginger (Zingiber officinale R.): chemical composition and antibacterial activity, Journal of Supercritical Fluids 80 (2013) 44-49.

[16] M.C. Lin, M.J. Tsai, K.C. Wen, Supercritical fluid extraction of flavonoids from Scutellariae Radix, Journal of Chromatography A 830 (1999) 387.

[17] Y.B. Zuo, A.W. Zeng, X.G. Yuan, K.T. Yu, Extraction of soybean isoflavones from soybean meal with aqueous methanol modified supercritical carbon dioxide, Journal of Food Engineering 89 (2008) 384. 